\title{
Reproductive Psychology and Infertility
}

Received: November 25, 2017; Accepted: November 30, 2017; Published: December 05, 2017

\section{Introduction}

Psychology as a profession is practised worldwide and is regulated by the social, cultural, educational, political and legal context of each country. However, we often face cross-border challenges in our daily practice which present a more universal shared setting [1]. This applies to professional psychology practice in the Reproductive Health context, in which new social needs and challenges constantly appear and are identified. These needs and challenges affect all nations equally but in a different way.

The extraordinary advances in assisted reproduction and the exponential growth in resources and assistance centers have exceeded the capacity for response of the different societies and cultures, and new challenges for reproductive health providers constantly arise, as well as the need to develop a globally consistent professional identity for psychologists in the healthcare context. Regarding the statements of the International Project on Core Competences in Professional Psychology [1], these needs comprise identifying the area involved, the proper resources, the psychological knowledge and techniques and the strategies to approach common problems.

Considering the individual cultural and legal contexts in which psychologists practice their profession in their corresponding countries, this short article aims to delimit the functions and competences associated with the psychologist's role in reproductive health, and especially those related to their work in the Reproductive Medicine and Assisted Human Reproduction (AHR) context.

\section{Psychology and Reproductive Health}

Reproductive psychology is a specialty of Health psychology, conducted within the framework of sexual and reproductive health, that deals with psychological aspects of human reproduction and its possible complications [2]. From adolescence to old age, we pass through distinct phases such as puberty, menarche, fatherhood, motherhood, or menopause, and various life situations that can produce emotional changes and require more specific psychological attention. Reproductive psychology provides an opportunity to look at and understand pregnancy, birth, the menstrual cycle and menopause, and sexual and reproductive events in older age, not merely as medical and biological processes, but as social and psychological events.

The application of the definition of "health" by the WHO to reproductive and sexual health is broad and deals with
Rosa María Limiñana-Gras*

Departament of Personality and

Psychological Assessment and Treatment, University of Murcia, Spain

\author{
*Corresponding author: \\ Rosa María Limiñana Gras \\ ” liminana@um.es \\ Departament of Personality and \\ Psychological Assessment and Treatment, \\ University of Murcia, Spain.
}

Tel: 868887722

Fax: 868884111

Citation: Limiñana-Gras RM (2017) Reproductive Psychology and Infertility. Acta Psychopathol Vol.3 No.S2:83

reproductive processes, systems and functions in all life stages [3]. It also includes other factors related to lifestyle, human rights, information and access to safe and effective methods ensuring sexual and reproductive health, as well as fertility control and access to services and educational programmes on sexual and reproductive health. As Van den Akker [4] points out, it can be deduced from this broad definition that "a focus on sexual and reproductive health is not a privilege, it is a necessity". People are sexual beings throughout their life, and sexual and reproductive healthcare must focus on improving life and personal relationships, and not be limited to counselling on procreation or sexually transmitted infections.

Reproductive psychology deals with different processes involved in psychological health, such as those involved in childbearing, adjustment to pregnancy or attitudes to motherhood and fatherhood. It also addresses psychological aspects of reproductive problems, such as premature birth, perinatal loss, congenital abnormalities and postnatal psychological complications, including postnatal depression and stress disorders and, of course, the psychological and social aspects of infertility diagnosis in females and in males. As with reproductive medicine, difficulties in having children, involuntary childlessness, and the overall care received in Assisted Human Reproduction (AHR), are central to reproductive psychology [2].

Psychological care in this context does not only comprise the required psychological assistance for the emotional responses caused by infertility diagnosis and treatment, but also the 
psychosocial consequences arising from that experience and the psychological needs of all individuals involved in the different AHR treatments and techniques: couples, infertile women or men, ovule donors, surrogate mothers, etc.

The main goal of psychologists in this context is to promote informed reproductive decision-making, and psychological health and well-being throughout all stages and aspects of the reproductive process. Support offered includes, among other services, sexual and reproductive health counselling, psychological support for infertility, follow-up and psychological care during the different psychological stages of assisted reproduction treatment, couple therapy, psychological evaluation and follow-up of donors, etc.

\section{Infertility}

Infertility and reproductive problems in general have become a major health concern affecting over $15 \%$ of people of reproductive age worldwide $[5,6]$. The important demographic and social changes in the last decades of the $20^{\text {th }}$ century have led to a very rapid and unprecedented change in the lives of women and men. These changes have long-term consequences for family planning, as new family models arise and coexist with traditional ones. In the labour market, women are increasingly entering the work environment and, although it may seem paradoxical, greater access to contraception coexists with a large both public and private offering of assisted reproduction. Greater access to education for women, resulting in them being better trained and qualified for the working world, and contraception availability have led to delayed motherhood and a corresponding increase in age. This has raised the incidence of reproductive dysfunction associated with ageing in men and women [7]. It is not therefore surprising that reproductive problems are becoming increasingly important in developed societies of the Western world, especially in ageing towns and many urban areas where women have their first child at older ages, which could become a major social problem [8].

Reproductive health affects the lives of women and men in all matters related to the reproductive system, its functions and processes. However, according to the United Nations [3], this involves not only people being able to lead a satisfactory risk-free sexual life, but also the ability to reproduce, and the freedom to decide about this. Despite the importance of this last aspect, infertility prevention and care are often considered as a secondary public health problem, especially in low-income countries [5].

The WHO started to deal with reproductive problems (infertility and sterility), to regulate fecundity (contraception) and to define and limit concepts and terminology [9] through its HRP Special Programme (Special Programme of Research, Development and Research Training in Human Reproduction). However, reproductive problems are more difficult to solve than reproduction control, where the efforts to solve them can take long and the result is not always as expected [10]. Due to the high complexity of the mechanisms involved for a sperm to fertilize an ovule, we can state that pregnancy is a miracle of nature. Compared to other species, human fecundity is much lower, and the probability of a young woman becoming pregnant in a cycle is around $20-25 \%$, gradually decreasing with age [11].
There is a great deal of information about sexuality, family planning and contraception, but people rarely consider the possibility of not being fertile. Reproductive problems may surprise many women who, after a sterility or infertility diagnosis, realize that fecundity control by using contraception had raised similar expectations to conception control, and they never imagined they would not be able to have children when they wished to. The ability to control contraception does not imply controlling the ability to conceive and for most women who chose a contraceptive method without knowing whether or not they were fertile, their diagnosis is unexpected, it brings into question their life expectations and beliefs and causes helplessness, blame, and lack of control over their lives.

The extraordinary advances in the assisted reproduction field, as well as the exponential growth of resources and public and private support centers, reproductive medicine and the different Assisted Reproduction Techniques (ARTs), offer multiple choices to men, women and couples with reproductive problems. Around $2 \%$ of conceptions in Europe are medically assisted, most of them being "in vitro" fertilizations (IVF) [12], but only $15-20 \%$ result in pregnancy at the first attempt [13]. The low success rate of ARTs makes these "solutions" a source of various stress factors which build up throughout the different treatments. IVF treatment, specifically, may become a long, painful and stressful process, during which frustration due to unfulfilled expectations, social pressure, helplessness, disappointment, hopelessness and downheartedness because of failure and the economic costs of the process may arise [14,15].

At present, there is considerable evidence suggesting that stress has important effects on the reproductive function. Suppression of the stress-associated reproductive function may lead to delayed menarche, hypothalamic amenorrhea, ovarian dysfunction or early onset perimenopause $[16,17]$. Most studies on stress and in vitro fertilization have identified a relationship between higher stress levels and a lower percentage of pregnancy and livebirths [18-20]. Stress exposure itself has even been directly related to conceptive failure [14] and considered as the most common reason for fertility treatment interruption [21].

In addition to physiological reactions, reproductive procedures and intervention success, stress causes emotional and cognitive responses which persist over time. These responses may have a significant impact on areas of vital importance to an individual (sexuality, family relationships, social relationships, work, etc.) and on their beliefs about motherhood or fatherhood, which may lead to a deterioration of psychological and adaptive resources [22].

Research in recent decades has significantly contributed to depathologisation of these problems and has focused on fostering health in the assisted reproduction context. However, assisted reproduction techniques in clinical practice are performed only through medical-biological procedures, and although psychological issues are considered to be important, they play a secondary role in diagnostic procedures as well as in infertility treatment [23]. The scientific-technical advances in assisted reproduction and the medicalization of infertility continue to grow disproportionately compared to attention paid to the emotional response of women and men facing this experience, alone or as a couple [24]. 
Reproductive complications are not usually a problem for the physical integrity or the life of people suffering from them. Unlike other reproductive health problems, infertility does not involve a previous morbid process, but it does affect women's or men's representations of the "internal world", and mainly, a wish or existential goal as old as mankind: the wish to be parents. Psychological suffering will mostly depend on the patient's personal and psychosocial characteristics. Quantifying

\section{References}

1 https://www.psykologforeningen.no/foreningen/english/ipcp.

2 Limiñana-Gras RM (2017) Health and gender perspective in infertility. The psychology of gender and health: conceptual and applied global concerns ( $1^{\text {st }}$ Edn by Sánchez-López MP, Limiñana-Gras RM). San Diego, CA: ELSEVIER, p: 430.

3 United Nations (1995) Programme of action adopted at the International conference on population \& development. Cairo, 5-13 September 1994, New York: United Nations Population Fund.

4 Van den Akker OB (2012) Reproductive health psychology. London (UK): John Wiley \& Sons, p: 378.

5 World Health Organization (2010) Mother or nothing: the agony of infertility. Bull World Health Organ 88: 881-882.

6 Inhorn MC, Patrizio P (2015) Infertility around the globe: new thinking on gender, reproductive technologies and global movements in the 21st century. Hum Reprod Update 21: 411-426.

7 Missmer SA, Abusief M, Barbieri RL, Goldman MB (2013) Infertility. Women and Health (2nd Edn by Goldman MB, Troisi R, Rexrode KM) Chapter 17, pp: 251-270.

8 Llavona LM (2008) El impacto psicológico de la infertilidad. Papeles del Psicólogo 29: 158-166.

9 Zegers-Hochschild F, Adamson GD, de Mouzon J, Ishihara O, Mansour $\mathrm{R}$, et al. (2009) International committee for monitoring assisted reproductive technology (ICMART) and the world health organization (WHO) revised glossary of ART terminology, 2009. Fertil steril 92: 1520-1524.

10 Berg BJ, Wilson JF (1991) Psychological functioning across stages of treatment for infertility. J Behav Med 14: 11-26.

11 Deep JP (2014) Assisted reproductive technology. J Chitwan Medical College 4: 1-10.

12 Hunfeld JAM, Passchier J, Bolt LLE, Buijsen MAJM (2004). Protect the child from being born: arguments against IVF from heads of the 13 licensed Dutch fertility centres, ethical and legal perspectives. J Reprod Infant Psychol 22: 279-289. such suffering and the resources available for the treatment approach should form part of the diagnostic and therapeutic procedures in reproductive medicine. Infertility and its treatment should be considered as a vital stressor event having unique characteristics, that should be dealt with from a multidisciplinary and multidimensional point of view, including the psychological, emotional, social and cultural needs of couples and individuals, whether men or women.

13 Verhaak CM, Smeenk JMJ, van Minnen A, Kremer JAM, Kraaimaat FW (2005) A longitudinal, prospective study on emotional adjustment before, during and after consecutive fertility treatment cycles. Human Reprod 20: 2253-2260.

14 Anderson K, Nisenblat V, Norman R (2010) Lifestyle factors in people seeking infertility treatment - a review. Aust N Z J Obstet Gynaecol 50: 8-20.

15 Moreno-Rosset C, Antequera R, Gómez Y (2009) La psicología de la reproducción: la necesidad del psicólogoen las unidades de reproducción humana [Reproductive Psychology: Psychologist in the Need for Human Reproduction Units]. Clínica y Salud, 20: 79-90.

16 Nakamura K, Sheps S, Arck P (2008) Stress and reproductive failure: past notions, present insights and future directions. J Assist Reprod Genet 25: 47-62.

17 Nepomnaschy PA, Sheiner E, Mastorakos G, Arck PC (2007) Stress, immune function, and women's reproduction. Ann NY Acad Sci 1113: 350-364.

18 Smeenk JM, Verhaak CM, Vingerhoets AJ, Sweep CG, Merkus JM, et al. (2005) Stress and outcome success in IVF: the role of self-reports and endocrine variables. Human Reprod 20: 991-996.

19 Klonoff-Cohen H, Chu E, Natarajan L, Sieber W (2001) A prospective study of stress among women undergoing in vitro fertilization or gamete intrafallopian transfer. Fertil Steril 76: 675-687.

20 Klonoff-Cohen H, Natarajan L (2004) The concerns during assisted reproductive technologies (CART) scale and pregnancy outcomes. Fertil Steril 81: 982-988.

21 Olivius C, Friden B, Borg G, Bergh C (2004) Why do couples discontinue in vitro fertilization treatment? a cohort study. Fertil Steril 81: 258-261.

22 Moura-Ramos M, Gameiro S, Canavarro MC, Soares I (2011) Assessing infertility stress: re-examining the factor structure of the fertility problem inventory. Human Reprod 27: 496-505.

23 Rich CW, Domar AD (2016) Addressing the emotional barriers to access to reproductive care. Fertil Steril 105: 1124-1127.

24 Cousineau TM, Domar AD (2007) Psychological impact of infertility. Best Pract Res Clin Obstet Gynaecol 21: 293-308. 